\title{
Chest Wall Resection for Adult Soft Tissue Sarcomas and Chondrosarcomas: Analysis of Prognostic Factors
}

\author{
Albertus N. van Geel • Michel W. J. M. Wouters • \\ Titia E. Lans • Paul I. M. Schmitz • \\ Cornelis Verhoef
}

Published online: 21 September 2010

(C) The Author(s) 2010. This article is published with open access at Springerlink.com

\begin{abstract}
Background Wide resection with tumor-free margins is necessary in soft-tissue sarcomas to minimize local recurrence and to contribute to long-term survival. Information about treatment outcome and prognostic factors of adult sarcoma requiring chest wall resection (CWR) is limited. Methods Sixty consecutive patients were retrospectively studied for overall survival (OS), local recurrence-free survival (LRFS), and disease-free survival (DFS). Twentyone prognostic factors regarding survival were analyzed by univariate analysis using the Kaplan-Meier method and the log-rank test.

Results With a median survival of 2.5 years, the OS was $46 \%(33 \%)$ at $5(10)$ years. The LRFS was $64 \%$ at 5 and 10 years, and the DFS was $30 \%$ and $25 \%$ at 5 and 10 years. At the end of the study period, 26 patients (43\%) were alive, of which 20 patients (33\%) had no evidence of disease and 40 patients $(67 \%)$ had no chest wall recurrence. In the group of 9 patients with a radiation-induced soft-tissue sarcoma, the median survival was 8 months. Favorable outcome in univariate analysis in OS and LRFS applied for the low-grade sarcoma, bone invasion, and sternal resection. For OS only, age below 60 years and no radiotherapy
\end{abstract}

A. N. van Geel $(\bowtie) \cdot$ T. E. Lans · C. Verhoef

Department of Surgical Oncology, Erasmus Medical Center/

Daniel den Hoed Cancer Center, Groene Hilledijk 301, 3075 EA

Rotterdam, The Netherlands

e-mail: a.n.vangeel@erasmusmc.nl

P. I. M. Schmitz

Department of Biostatistics, Erasmus Medical Center/Daniel den

Hoed Cancer Center, Rotterdam, The Netherlands

M. W. J. M. Wouters

Department of Surgery, Netherlands Cancer Institute/Antoni van Leeuwenhoek Hospital, Amsterdam, The Netherlands were significant factors contributing to an improved survival. CWR was considered radical (R0) at the pathological examination in 43 patients. There were 52 patients with an uneventful recovery. There was one postoperative death. Conclusions CWR for soft-tissue sarcoma is a safe surgical procedure with low morbidity and a mortality rate of less than $1 \%$. With proper patient selection acceptable survival can be reached in a large group of patients. Care must be given to patients with radiation-induced soft-tissue sarcoma who have a significantly worse prognosis.

\section{Introduction}

Soft-tissue sarcomas (STS) account for approximately $1 \%$ of all malignancies in adults. STS involving the chest wall, ribs, or sternum and overlying soft tissue are rare. In a large series of 437 STS patients without metastases, only 17 were located in the chest wall [1].

STS are best treated by wide local excision and radiotherapy [2], which means that most of the STS of the chest wall need a full-thickness chest wall resection (CWR), perhaps in combination with skeletal reconstruction and soft tissue coverage, to obtain negative margins. Surgical treatment may be preceded or followed by radiotherapy according to local protocols, especially when narrow margins are expected or confirmed in the pathological specimen. There is no indication for (neo-) adjuvant chemotherapy except in prospective randomized trials.

The etiology of a STS is unknown, except in those patients who were treated in the past with radiotherapy for breast cancer or Hodgkin's disease. The cumulative radiotherapy-induced STS (RISTS) incidence is reported to be $0.07 \%$ at 5 years, $0.27 \%$ at 10 years, and $0.48 \%$ at 15 years after radiotherapy treatment [3]. 
Information about treatment and prognosis of adult STS located in the chest wall is limited, especially in cases with a full-thickness CWR. Only a few series are published in which the patients were collected over decades. In some of these series a substantial number of patients are children or adolescents with so-called small-cell sarcomas for whom the preferred treatment is salvage surgery after chemotherapy.

The aim of this study was to describe the factors that influence prognosis in adult STS patients in whom a CWR was performed. A relatively large group of these patients have been treated at our institute and therefore our experience can contribute to the treatment of patients worldwide.

\section{Methods}

A retrospective study was performed using a database of 229 consecutive patients surgically treated at the Daniel den Hoed Cancer Center with a CWR for a tumor or a radiation ulcer of the chest wall between 1986 and 2006. Sixty-six patients were identified as having a soft-tissue tumor. Because of the standard primary treatment of chemotherapy, Ewing's and other so-called small-cell sarcomas were excluded from this study $(n=6)$. Two patients developed a local recurrence treated by a second CWR: only the first CWR is included in this study.

A CWR was defined as a resection of at least one costa and/or the sternum or a wide soft-tissue resection requiring reconstruction (Fig. 1). If necessary, several types of inlays were used for skeletal reconstruction during the 20 years of this study. The first few years homologous dura mater was used (Lyodura $\left.{ }^{\circledR}\right)$, later replaced by polyurethane (Neuropatch $\AA)$ as an artificial inlay. In some cases polyglactine (Vicryl $\left.{ }^{\circledR}\right)$ was used. Patients operated on after 2004 received a double-layer polypropylene-PTFE mesh (Composix $®)$. Standard soft-tissue reconstruction was performed with a pedicled omentoplasty, unless primary closure could be established.

Patient demographics, pathology records, data on the surgical and (neo-) adjuvant treatment, postoperative morbidity, mortality, involvement of the resection margins, and length of follow-up were retrieved from the original patient files. Surgical aspects of the CWR technique performed in our hospital have been described earlier [4].

The end points of this study were overall survival (OS), disease-free survival (DFS), and local recurrence-free survival (LRFS). Univariate analysis was performed using the Kaplan-Meier method, the log-rank test, and the univariate Cox proportional hazards model. The outcome of patients who had postoperative radiotherapy in different subgroups was also studied: all patients excluding $\operatorname{RISTS}(n=9)$, because in this group radiotherapy was no longer possible; all patients excluding borderline tumors $(n=14)$, because these patients potentially do not develop metastases; and patients with free (R0) and involved (R1 and R2) resection margins. Significance was set at $p \leq 0.05$. All the statistical analyses were performed using Stata version 9.2 (Stata Corporation, College Station, TX, USA).

\section{Results}

Sixty consecutive patients met the inclusion criteria of this study. There were 24 males and 36 females, ranging in age from 21 to 91 years. All but four patients underwent CWR with curative intent.

Two groups of patients were distinguished according to the grade of their tumor [5]. The low-grade group $(n=22)$ included grade I STS and patients with a borderline tumor like desmoid tumors and dermatofibrosarcoma protuberans. The high-grade group ( $n=38)$ consisted of grade II and III STS, including 9 patients with a radiation-induced STS (RISTS).

In 11 patients the CWR consisted of an extended softtissue excision and reconstruction. In 27 patients three or more costae were removed. In 13 patients the CWR was performed including a (sub-) total sternectomy. In 13 patients the chest wall did not need to be reconstructed after the resection because the bony defect was too small. In some cases the defect was located under the scapula securing sufficient rigidity of the thorax. In 16 patients the
Fig. 1 High-grade sarcoma of the anterior chest wall treated by anterior chest wall resection and subtotal sternectomy followed by chest wall reconstruction (artificial inlay, pedicled omentoplasty, and meshed split skin graft)
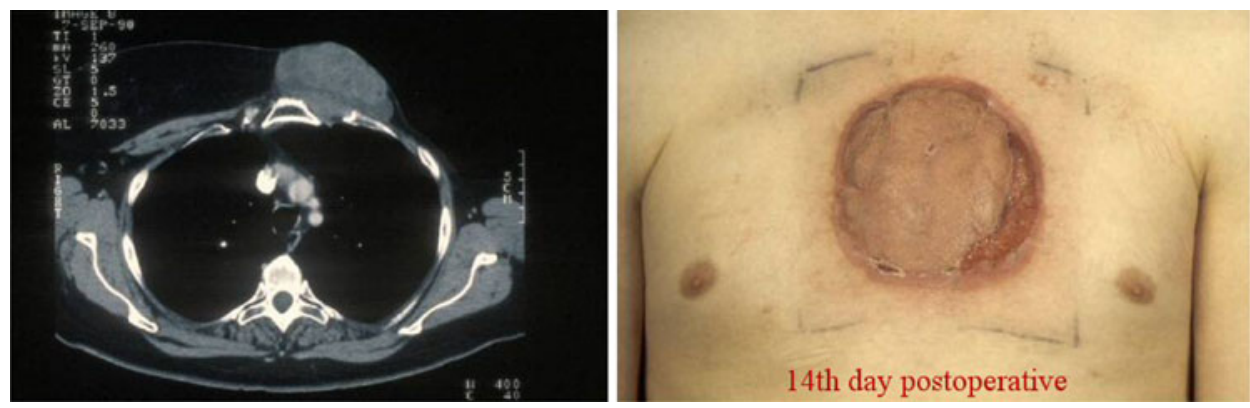
overlying soft tissue needed reconstruction and/or skin transplantation.

At pathological examination bone invasion was seen in 23 patients. The CWR was considered radical with free resection margins (R0) in 43 patients. In 10 patients the CWR was microscopically irradical with involved resection margins ( $\mathrm{R} 1$ resection), and in 7 patients a palliative resection was performed leading to gross involvement of tumor in the margins ( $\mathrm{R} 2$ resection).

Sixteen patients, all in the high-grade STS group, had postoperative radiotherapy. None of the patients received chemotherapy.

There were 52 patients with an uneventful recovery or minor complications and 8 patients with serious postoperative complications. One patient with serious lung complications from ARDS required long-lasting artificial ventilation. Another patient developed pneumonia followed by cardiac failure with a fatal outcome. The artificial inlay for chest wall stabilization was removed in three of five patients after partial necrosis and subsequent infection of the wound.

The median follow-up for all patients was 1.7 years (range $=2-247$ months), and for the patients alive at the end of the study it was 2.7 years (range $=4-247$ months). Median survival was 2.5 years. Overall survival (OS), local recurrence-free survival (LRFS), and disease-free survival (DFS) were 46, 64, and $30 \%$ at 5 years and 33, 64, and $25 \%$ at 10 years, respectively. At the end of the study period, 26 patients were alive, of which 20 patients had no evidence of disease and 40 patients had no local recurrence.

The outcome of the statistical analysis for factors with a positive influence on survival is presented in Table 1. In univariate analysis regarding OS and LRFS, a low-grade sarcoma, bone invasion, and sternal resection lead to a favorable prognosis (Fig. 2). Younger age ( $<60$ years) and no postoperative radiotherapy are favorable prognostic factors for the OS. Although resection margin was not a significant factor, this margin could be difficult to confirm in some cases with very diffuse or multifocal tumors, like angiosarcomas. This so-called clinical radicality was a significant factor for LRFS. The difference in survival curves for curative and palliative CWR just did not reach a significant value $(p=0.051)$.

The effect of postoperative radiotherapy was studied separately in the following groups: (1) all patients without a RISTS, (2) all patients with a borderline tumor, (3) all R0 margins, and (4) all $\mathrm{R} 1$ and $\mathrm{R} 2$ resection margins. OS remained significantly improved for all 51 patients without RISTS and all patients without a borderline tumor receiving radiotherapy (Table 2 ).

Local recurrences were seen in $20 / 60$ patients $(33 \%)$; in $16 / 38$ patients $(42 \%)$ with a high-grade sarcoma and $6 / 22$ patients $(27 \%)$ with a low-grade sarcoma. All recurrences occurred within 12 months, except one patient with a highgrade STS (22 months). The median time to local recurrence for RISTS was 4 months. Two of the patients with a low-grade sarcoma underwent a second CWR for recurrent disease and remained free of disease until the end of the study period.

Distant metastases developed in 33 patients (48\%). Of these patients only four had nonborderline low-grade STS.

Four patients underwent a CWR for palliative reasons. They survived 5, 11, 17, and 28 months, three of them with adequate local tumor control.

In the 9 patients with a RISTS (high-grade), the median survival was 8 months. Two patients who had a palliative CWR for RISTS lived 11 and 17 months and the second patient developed a local recurrence after 11 months.

\section{Discussion}

Our series of 60 patients with STS requiring CWR had a 5 -year survival rate of $46 \%$. High-grade tumors had a significantly worse prognosis $(5$-year OS $=23 \%$ ) compared to low-grade STS (5-year OS $=85 \%$ ). The morbidity rate was acceptably low, with one case of in-hospital mortality.

Most CWRs for sarcomas are performed in chondrosarcoma patients [6-9]. These chondrosarcomas are often low-grade tumors and therefore have a relatively good prognosis. In patients with low-grade STS, a 5-year OS of $67-80 \%$ has been described [6, 8-10]; in our study a 5-year OS of $85 \%$ was obtained. In the high-grade patient group, the OS is obviously worse, with the 5-year OS varying from 7 to $59 \%$ [7, 11-13]. Our study showed for all patients a 10 -year OS of $33 \%$, which is much lower than the $67-80 \%$ reported in literature $[6,14]$, with no 10 -year survivors in the high-grade STS group. These different outcomes can be explained only by selection bias.

Current literature provides hardly any data for prognostic factors other than tumor grade; our study's analysis can provide surgeons with more data to make an evidencebased decision for their future patients (Table 3). Distinctly negative prognostic factors that reached significance in univariate analysis for overall, local recurrence-free, and disease-free survival were pathological grade II/III (for all $p<0.0001$ and confirmed by others [13, 14]), no sternal resection, and no tumor invasion in bones confirmed by pathological examination. Since tumor grade is a wellaccepted prognostic factor in sarcoma surgery, we could expect this outcome. In our opinion, there is no logical explanation for bone invasion and sternal resection as prognostic favorable factors. Perhaps some primary (nonosteo-) sarcomas of the bone have a better outcome than soft-tissue sarcomas. However, in this retrospective study we were unable to identify sarcomas as primary bone 
Table 1 Prognostic factors for survival of 60 patients with chest wall resection for soft tissue sarcoma and chondrosarcoma

\begin{tabular}{|c|c|c|c|c|c|c|c|}
\hline \multirow[t]{2}{*}{ Covariate $(n=)$} & & \multicolumn{3}{|c|}{ Overall survival } & \multicolumn{3}{|c|}{ Local recurrence-free survival } \\
\hline & & HR & $95 \%$ CI HR & $p$ & HR & $95 \%$ CI HR & $p$ \\
\hline \multirow[t]{2}{*}{ Gender } & Female (36) & 1 & $0.32-1.32$ & 0.23 & 1 & $0.17-1.36$ & 0.16 \\
\hline & Male (24) & 0.65 & & & 0.48 & & \\
\hline \multirow[t]{2}{*}{ Age } & $<60$ years $(40)$ & 1 & $1.19-4.68$ & 0.01 & 1 & $0.34-2.70$ & 0.93 \\
\hline & $\geq 60$ years $(20)$ & 2.36 & & & 0.96 & & \\
\hline \multirow[t]{2}{*}{ Indication } & Curative (56) & 1 & $0.95-7.93$ & 0.051 & 1 & $0.46-8.71$ & 0.35 \\
\hline & Palliative (4) & 2.75 & & & 2.00 & & \\
\hline \multirow[t]{2}{*}{ Diameter $^{\mathrm{a}}$} & $\leq 5 \mathrm{~cm}(27)$ & 1 & $0.71-2.91$ & 0.32 & 1 & $0.35-2.37$ & 0.86 \\
\hline & $>5 \mathrm{~cm}(30)$ & 1.43 & & & 0.91 & & \\
\hline \multirow[t]{2}{*}{ Resection } & Soft tissue (11) & 1 & $0.21-1.10$ & 0.08 & 1 & $0.14-1.14$ & 0.08 \\
\hline & Bone/soft tissue (49) & 0.48 & & & 0.40 & & \\
\hline \multirow[t]{2}{*}{ Number of costae } & $1,2(33)$ & 1 & $0.35-1.42$ & 0.33 & 1 & $0.22-1.55$ & 0.27 \\
\hline & $3,4,5(27)$ & 0.71 & & & 0.58 & & \\
\hline \multirow[t]{2}{*}{ Sternum resection } & No (47) & 1 & $0.046-0.54$ & 0.001 & 1 & $0.02-1.18$ & 0.04 \\
\hline & Yes (13) & 0.16 & & & 0.16 & & \\
\hline \multirow[t]{2}{*}{ Lung resection } & No (55) & 1 & $0.36-3.90$ & 0.79 & 1 & $0.28-5.26$ & 0.81 \\
\hline & Yes (5) & 1.18 & & & 1.20 & & \\
\hline \multirow[t]{2}{*}{ Reconstruction bone } & No (13) & 1 & $0.28-1.30$ & 0.19 & 1 & $0.22-1.72$ & 0.35 \\
\hline & Yes (47) & 0.60 & & & 0.62 & & \\
\hline \multirow[t]{2}{*}{ Reconstruction soft tissue } & No (44) & 1 & $0.86-3.88$ & 0.11 & 1 & $0.57-4.52$ & 0.37 \\
\hline & Yes (16) & 1.83 & & & 1.60 & & \\
\hline \multirow[t]{2}{*}{ Grade } & I (22) & 1 & $4.57-82.03$ & $<0.0001$ & 1 & $1.62-31.19$ & 0.003 \\
\hline & II/III (38) & 19.36 & & & 7.10 & & \\
\hline \multirow[t]{2}{*}{ Bone invasion (pathol) } & No (37) & 1 & $0.21-0.95$ & 0.03 & 1 & $0.06-0.78$ & 0.01 \\
\hline & Yes (23) & 0.45 & & & 0.22 & & \\
\hline \multirow[t]{2}{*}{ Radical (pathol) } & No (17) & 1 & $0.80-3.30$ & 0.18 & 1 & $0.55-3.97$ & 0.43 \\
\hline & Yes (43) & 1.62 & & & 1.48 & & \\
\hline \multirow[t]{2}{*}{ Radical (clinical) } & No (20) & 1 & $0.27-1.09$ & 0.08 & 1 & $0.12-0.80$ & 0.01 \\
\hline & Yes (40) & 0.54 & & & 0.31 & & \\
\hline \multirow[t]{2}{*}{ Radiotherapy $^{\mathrm{b}}$} & No (44) & 1 & $0.12-4.58$ & 0.02 & 1 & $0.73-4.94$ & 0.18 \\
\hline & Yes (16) & 2.26 & & & 1.90 & & \\
\hline \multirow[t]{2}{*}{ Complication } & No (47) & 1 & $0.51-2.52$ & 0.75 & 1 & $0.21-2.48$ & 0.60 \\
\hline & Yes (13) & 1.14 & & & 0.72 & & \\
\hline \multirow[t]{2}{*}{ Complication serious } & No (52) & 1 & $0.30-2.44$ & 0.77 & 1 & $0.22-4.22$ & 0.97 \\
\hline & Yes (8) & 0.85 & & & 0.97 & & \\
\hline
\end{tabular}

${ }^{a}$ Data of three patients missing

b See also Table 2

sarcomas or not. Other factors that might influence prognosis are radical resection [10,12,14] (confirmed in our series only for LRFS in the clinical radical group), tumor size less than $5 \mathrm{~cm} \mathrm{[14],} \mathrm{age} \mathrm{[10]} \mathrm{(in} \mathrm{our} \mathrm{series} \mathrm{for} \mathrm{OS),}$ synchronous metastases [10], and local recurrence [10], although the latter prognostic factor could not be confirmed in another study [12].

The best results in STS surgery in the extremities are seen in patients with a R0 resection. The margin for sarcoma resection is the subject of current discussion and at present $2 \mathrm{~cm}$ is considered to be sufficient [2].Nevertheless, when the tumor invades the bony chest wall, this margin will not be reached at the inner side. Therefore, a minor margin is accepted as radical here, even when tumor is seen at the level of the pleura. If the resection margin is not free in its tangential way, the need of re-resection is questionable, since no statistical difference in outcome was found between pathological radical (R0) and irradical (R1 and R2) CWR (5-year OS of 25 and 20\%, respectively, in the high-grade group). 

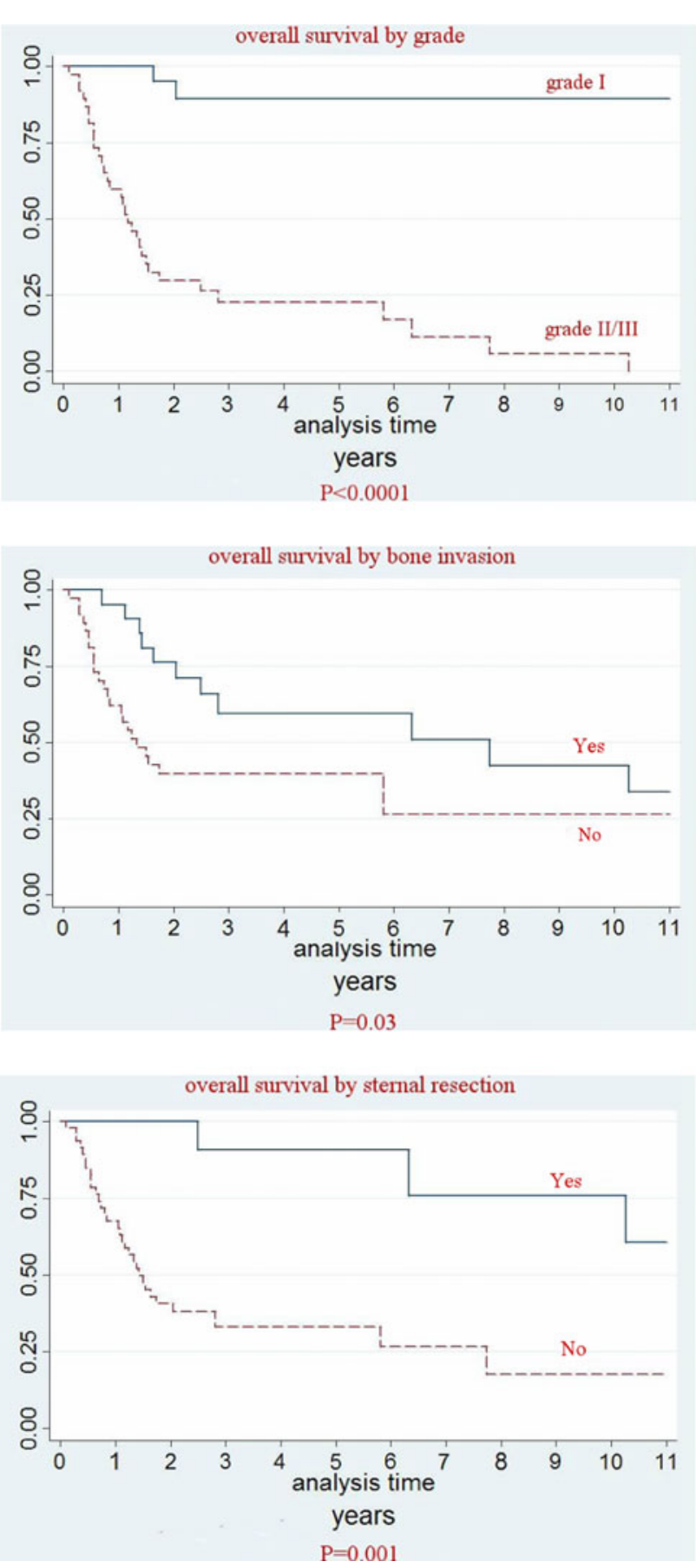

Fig. 2 Overall survival of chest wall resection for soft tissue sarcoma and chondrosarcoma by grade, bone invasion, and sternal resection

OS in all patients with postoperative radiotherapy is significantly worse $(p=0.02)$, but LRFS is not $(p=0.18)$. This finding is in contrast with the results for extremity sarcomas, in which radiotherapy improves local control but not the overall survival $[15,16]$. It has also been found that prognosis of chest wall sarcomas is similar to that of extremity sarcomas [11]. These different outcomes are explained probably by selection bias. The 60 selected patients in our study may be an unfavorable group. This remarkable result was further studied in subgroups of patients who did or did not have radiotherapy. Table 2 shows that there was no difference between the $\mathrm{R} 0$ and $\mathrm{R} 1 / 2$ groups. The OS remained significant for all 51 patients without RISTS and for all patients without borderline tumors. These findings are an important contribution to the existing literature concerning the role of radiotherapy in CWR.

A radical resection is advised only for chondrosarcomas: the 5-year survival rate was $100 \%$ for R0 resections compared to $50 \%$ for irradical resections [8].

In the literature, complication rates after CWR for STS are very low and comparable with our complication rate of $12 \%$, including one postoperative death. A postoperative death was also reported in another series of 16 patients [9, 13]. The risk for adverse events is lower than that for CWR for recurrent breast cancer [9]. The reason for this is probably the higher number of ulcerating tumors in breast cancer patients, leading to an increased risk for infectious complications [17].

In our series the prognosis for CWR in radiationinduced STS was poor compared to other series. The overall survival of 9 patients in our study ( 8 patients after breast cancer and 1 patient after Hodgkin's disease) ranged between 2 and 26 (median $=8$ ) months. Other reports show an actuarial 5-year survival of $36 \%$, and after a median follow-up of 30 months, a 5-year survival of $48 \%$ $[3,18]$. A possible explanation for our relatively poor outcome could be the extensive tumor growth in our group of patients and the fact that they did not receive radiotherapy after CWR. Based on the results of our series, one could argue that a CWR is indicated in this group of patients only as a palliative procedure.

Reconstruction of the chest wall for stabilization is carried out for defects of more than one rib, although even larger defects on the posterior side do not require reconstruction. For reconstruction of the rigid chest wall several biologic (absorbable; Lyodura ${ }^{\circledR}$,) and synthetic materials (absorbable such as Vicryl ${ }^{\circledR}$ and Dexon ${ }^{\circledR}$, and nonabsorbable such as Prolene ${ }^{\circledR}$, Marlex ${ }^{\circledR}$, Gore-Tex ${ }^{\circledR}$ ) and even combinations are available. Even a rigid reconstruction can be used (metal, methylmethacrylate). The best method is still being debated but the general thought is that absorbable materials do not pose wound problems in case of infection and the reconstruction is easier and faster. Nonrigid reconstruction is sufficient to temporarily stabilize the chest wall, enhance the respiratory function, and help the recovery of the patient. After CWR, lung function is reduced by about $10 \%$ [9].

The result of this study (and the experience in the entire series of 229 patients [17]) is that our method of reconstruction is safe and that a time-consuming skeletal reconstruction with rigid materials like steel or bone cement in combination with Marlex ${ }^{\circledR}$ is not necessary $[6,9]$. 
Table 2 Radiotherapy as a prognostic factor in subgroups of patients with chest wall resection for soft tissue sarcoma and chondrosarcoma

\begin{tabular}{|c|c|c|c|c|c|c|c|}
\hline \multirow[t]{2}{*}{ Covariate } & \multirow[t]{2}{*}{ Radiotherapy } & \multicolumn{3}{|c|}{ Overall survival } & \multicolumn{3}{|c|}{ Local recurrence-free survival } \\
\hline & & HR & $95 \%$ CI HR & $p$ & HR & $95 \%$ CI HR & $p$ \\
\hline \multirow[t]{2}{*}{$\operatorname{Exc} \operatorname{RISTS}^{\mathrm{a}}(n=51)$} & No & 1 & $0.13-5.32$ & 0.02 & 1 & $0.84-7.11$ & 0.09 \\
\hline & Yes & 2.45 & & & 2.44 & & \\
\hline \multirow[t]{2}{*}{ Exc Borderline $^{\mathrm{b}}(n=46)$} & No & 1 & $1.17-5.28$ & 0.01 & 1 & $0.74-5.22$ & 0.17 \\
\hline & Yes & 2.49 & & & 1.96 & & \\
\hline \multirow[t]{2}{*}{$\operatorname{RO} 3(n=43)$} & No & 1 & $0.59-5.90$ & 0.28 & 1 & $0.23-5.77$ & 0.86 \\
\hline & Yes & 1.86 & & & 1.16 & & \\
\hline \multirow[t]{2}{*}{$\mathrm{R} 1$ and $\mathrm{R} 2^{\mathrm{c}}(n=17)$} & No & 1 & $0.92-6.62$ & 0.06 & 1 & $0.69-7.71$ & 0.16 \\
\hline & Yes & 2.46 & & & 2.30 & & \\
\hline
\end{tabular}

${ }^{a}$ All patients excluding radiation-induced soft tissue sarcoma

b All patients excluding borderline tumors

${ }^{c}$ Resection margin is free (R0), microscopically involved (R1), grossly involved (R2)

Table 3 Review of the literature of chest wall resection for soft tissue sarcoma and chondrosarcoma

\begin{tabular}{|c|c|c|c|c|}
\hline \multirow[t]{2}{*}{ Author (year) [Ref] } & \multirow[t]{2}{*}{$n$} & \multicolumn{2}{|c|}{$\%$ Overall survival and (disease-free survival) } & \multirow[t]{2}{*}{ Remarks } \\
\hline & & 5 -year & 10-year & \\
\hline Perry (1990) [12] & 28 & $59(40)$ & & $\begin{array}{l}\text { Only high-grade sarcomas, including } \\
\text { recurrent sarcomas }\end{array}$ \\
\hline Gordon (1991) [11] & 149 & $\begin{array}{l}90 \text { low-grade } \\
49 \text { high-grade }\end{array}$ & & \\
\hline Burt (1992) [10] & 88 & 64 & & Chondrosarcomas \\
\hline Martini (1996) [7] & & $\begin{array}{l}80 \\
64 \text { Curative low-grade } \\
7 \text { Curative high-grade }\end{array}$ & & Median follow-up 17 years \\
\hline Chapelier (1997) [18] & 15 & $48(27)$ & & $\begin{array}{l}\text { Including radiation-induced sarcomas } \\
\text { Median follow-up } 30 \text { months }\end{array}$ \\
\hline Sabanathan (1997) [6] & 22 & & 67 & Chondrosarcomas \\
\hline Athenassiadi (2001) [19] & 8 & 33 & & \\
\hline Bricolli (2002) [9] & 16 & 86 & & $\begin{array}{l}\text { Chondrosarcomas } \\
\text { Median follow-up } 54 \text { months }\end{array}$ \\
\hline Fong (2004) [8] & 24 & $\begin{array}{l}92 \\
100 \text { radical } \\
50 \text { irradical }\end{array}$ & & Chondrosarcomas \\
\hline Kirova (2005) [3] & 8 & Median $40 \mathrm{~m}$ & & Radiation-induced (osteo) sarcomas \\
\hline Gross (2005) [14] & 55 & $87(75)$ & $80(64)$ & 28 primary and 27 recurrent sarcomas \\
\hline Pfannschmidt (2006) [13] & 25 & $\begin{array}{l}57 \\
42 \text { high-grade }\end{array}$ & & $\begin{array}{l}\text { Median survival all patients } 100 \text { months } \\
\text { Median survival high-grade } 36 \text { months }\end{array}$ \\
\hline van Geel (this series) & 60 & $\begin{array}{l}46(28) \\
85 \text { (72) low-grade } \\
23 \text { (10) high-grade }\end{array}$ & $\begin{array}{c}30(25) \\
85(72) \\
6(-)\end{array}$ & Median follow-up 1.7 years and survival 2.5 years \\
\hline
\end{tabular}

\section{Conclusion}

Despite the fact that most sarcomas of the chest wall are voluminous tumors, a chest wall resection is a safe surgical procedure with low morbidity and a mortality rate of less than $1 \%$. After diagnosing a patient with a tumor of the chest wall, the patient's case should be discussed by a multidisciplinary group, including a surgeon, pathologist, radiologist, radiotherapist, medical oncologist, and plastic surgeon, to confirm optimal treatment planning and reconstructive possibilities. Even in isolated local recurrences, a second CWR can be considered. In patients with 
systemic disease, a CWR can be considered for palliative reasons, for example, to maintain local tumor control in case of substantial tumor burden in the chest wall.

Open Access This article is distributed under the terms of the Creative Commons Attribution Noncommercial License which permits any noncommercial use, distribution, and reproduction in any medium, provided the original author(s) and source are credited.

\section{References}

1. Torosian MH, Friedrich C, Godbold J et al (1988) Soft-tissue sarcoma: initial characteristics and prognostic factors in patients with and without metastatic disease. Semin Surg Oncol 4:13-19

2. Flugstad DL, Wilke CP, McNutt MA et al (1999) Importance of surgical resection in the successful management of soft tissue sarcoma. Arch Surg 134:856-861

3. Kirova YM, Vilcoq JR, Asselain B et al (2005) Radiationinduced sarcomas after radiotherapy for breast carcinoma: a large-scale single-institution review. Cancer 104:856-863

4. Contant CM, van Geel AN, van der Holt B et al (1996) The pedicled omentoplasty and split skin graft (POSSG) for reconstruction of large chest wall defects. A validity study of 34 patients. Eur J Surg Oncol 22:532-537

5. Trojani M, Contesso G, Coindre JM et al (1984) Soft-tissue sarcomas of adults; study of pathological prognostic variables and definition of a histopathological grading system. Int J Cancer 33: $37-42$

6. Sabanathan S, Shah R, Mearns AJ (1997) Surgical treatment of primary malignant chest wall tumours. Eur J Cardiothorac Surg 11:1011-1016

7. Martini N, Huvos AG, Burt ME et al (1996) Predictors of survival in malignant tumors of the sternum. J Thorac Cardiovasc Surg 111:96-105
8. Fong YC, Pairolero PC, Sim FH et al (2004) Chondrosarcoma of the chest wall: a retrospective clinical analysis. Clin Orthop Relat Res (427):184-189

9. Briccoli A, De Paolis M, Campanacci L et al (2002) Chondrosarcoma of the chest wall: a clinical analysis. Surg Today 32: 291-296

10. Burt M, Fulton M, Wessner-Dunlap S et al (1992) Primary bony and cartilaginous sarcomas of chest wall: results of therapy. Ann Thorac Surg 54:226-232

11. Gordon MS, Hajdu SI, Bains MS et al (1991) Soft tissue sarcomas of the chest wall. Results of surgical resection. J Thorac Cardiovasc Surg 101:43-54

12. Perry RR, Venzon D, Roth JA et al (1990) Survival after surgical resection for high-grade chest wall sarcomas. Ann Thorac Surg 49:363-368

13. Pfannschmidt J, Geisbusch P, Muley T et al (2006) Surgical treatment of primary soft tissue sarcomas involving the chest: experiences in 25 patients. Thorac Cardiovasc Surg 54:182-187

14. Gross JL, Younes RN, Haddad FJ et al (2005) Soft-tissue sarcomas of the chest wall: prognostic factors. Chest 127:902-908

15. Pisters PW, Leung DH, Woodruff J et al (1996) Analysis of prognostic factors in 1, 041 patients with localized soft tissue sarcomas of the extremities. J Clin Oncol 14:1679-1689

16. Yang JC, Chang AE, Baker AR et al (1998) Randomized prospective study of the benefit of adjuvant radiation therapy in the treatment of soft tissue sarcomas of the extremity. J Clin Oncol 16:197-203

17. Lans TE, van der Pol C, Wouters MJWM et al (2009) Complications in wound healing after chest wall resection in cancer patients: a multivariate analysis of 220 patients. J Thor Oncol 4: 639-643

18. Chapelier AR, Bacha EA, de Montpreville VT et al (1997) Radical resection of radiation-induced sarcoma of the chest wall: report of 15 cases. Ann Thorac Surg 63:214-219

19. Athanassiadi K, Kalavrouziotis G, Rondogianni D et al (2001) Primary chest wall tumors: early and long-term results of surgical treatment. Eur J Cardiothorac Surg 19:589-593 